\title{
Analysis of ERCC1, BRCA1, RRM1 and TUBB3 as predictors of prognosis in patients with non-small cell lung cancer who received cisplatin-based adjuvant chemotherapy: A prospective study
}

\author{
ZHI-LIANG HUANG ${ }^{1,2^{*}}, \mathrm{XUN} \mathrm{CAO}^{1,3^{*}}, \mathrm{RUO} \mathrm{ZHEN} \mathrm{LUO}{ }^{1,4}$, \\ YOU-FANG CHEN ${ }^{5}$, LIN-CHUN ZHU ${ }^{1}$ and ZHESHENG WEN ${ }^{1}$
}

\begin{abstract}
${ }^{1}$ Department of Thoracic Oncology, Sun Yat-Sen University Cancer Center, State Key Laboratory of Oncology in South China, Collaborative Innovation Center of Cancer Medicine, Guangzhou, Guangdong 510060; ${ }^{2}$ Xiamen Medical Center, Zhongshan Hospital, Fudan University, Xiamen, Fujian 361015; Departments of ${ }^{3}$ Critical Care Medicine and ${ }^{4}$ Pathology, Sun Yat-Sen University Cancer Center, Guangzhou, Guangdong 510060; ${ }^{5}$ Graceland Medical Centre, The Sixth Affiliated Hospital of Sun Yat-Sen University, Guangzhou, Guangdong 510623, P.R. China
\end{abstract}

Received August 20, 2014; Accepted May 8, 2015

DOI: $10.3892 / 01.2015 .3894$

\begin{abstract}
Although adjuvant platinum-based chemotherapy has been demonstrated to improve survival in patients with completely resected non-small cell lung cancer (NSCLC), individualized approaches to therapy are urgently required to improve the treatment efficacy and reduce unnecessary toxicity. It was hypothesized in the present study that the protein levels of excision repair cross-complementation group 1 (ERCC1), breast cancer 1 (BRCA1), ribonucleotide reductase M1 (RRM1) and class III $\beta$-tubulin (TUBB3) may influence the therapeutic effect of adjuvant cisplatin-based chemotherapy. The expression of ERCC1, BRCA1, RRM1 and TUBB3 in tissues obtained from 84 patients with NSCLC was analyzed in the present non-interventional study by immunohistochemistry prior to adjuvant chemotherapy. All patients received adjuvant cisplatin-based chemotherapy. The primary endpoint in the present study was disease free survival (DFS). Out of the 84 tumors, the expression of ERCC1, BRCA1, RRM1 and TUBB3 was identified in 46 (55\%), 11 (13\%), $73(87 \%)$ and $76(90 \%)$ tissues, respectively. A beneficial response to adjuvant cisplatin-based chemotherapy in DFS was associated with the absence of the expression of ERCC1 [hazard ratio (HR), 2.166; 95\% confidence interval (CI), 1.049-4.474; $\mathrm{P}=0.037]$ and BRCA1 (HR, 2.419; 95\% CI,
\end{abstract}

Correspondence to: Dr Zhesheng Wen, Department of Thoracic Oncology, Sun Yat-Sen University Cancer Center, State Key Laboratory of Oncology in South China, Collaborative Innovation Center of Cancer Medicine, 651 Dongfeng Road East, Guangzhou, Guangdong 510060, P.R. China

E-mail: wenzhsh@sysucc.org.cn

*Contributed equally

Key words: non-small cell lung cancer, breast cancer 1, excision repair cross-complementation group 1, ribonucleotide reductase M1, class III $\beta$-tubulin
1.127-5.193; $\mathrm{P}=0.023)$, but not with the expression status of RRM1 (HR, 0.568; 95\% CI, 0.234-1.379; P=0.212) or TUBB3 (HR, 1.874; 95\% CI, 0.448-7.842; $\mathrm{P}=0.39$ ). In addition, patients lacking the expression of ERCC1 and BRCA1 benefited more from adjuvant cisplatin-based chemotherapy compared with patients that expressed either ERCC1 or BRCA1 (HR, 3.102; 95\% CI, 1.343-7.163; $\mathrm{P}=0.008)$. The expression of ERCC1 and BRCA1 was significantly associated with the DFS time in patients with NSCLC treated with adjuvant cisplatin-based chemotherapy, respectively. The combination of the ERCC1 and BRCA1 expression levels may be a promising prognostic prediction for adjuvant cisplatin-based chemotherapy.

\section{Introduction}

Lung cancer, which is the most frequently diagnosed cancer worldwide, is the leading cause of cancer-associated mortality in males and is also common in females worldwide $(1,2)$. Therefore, improvements in the diagnosis and treatment of lung cancer are urgently required. Overall, 80\% of lung cancer lesions are diagnosed as non-small cell lung cancer (NSCLC) (3). Currently, complete surgical resection with adjuvant platinum-based chemotherapy is the standard treatment for patients with resected stage II or IIIa NSCLC $(4,5)$. However, various toxicities occur in post-operative chemotherapy and the overall survival time varies in patients, even in those at the same stage of NSCLC and with the same histological type of cancer (6). Previously, studies have reported that genetic biomarkers, such as excision repair cross-complementation group 1 (ERCC1), breast cancer 1 (BRCA1), ribonucleotide reductase M1 (RRM1) and class III $\beta$-tubulin (TUBB3), are closely associated with the clinical outcome of patients administered with chemotherapy $(7,8)$.

One of the major determinants of cisplatin resistance is the nucleotide excision repair capacity. In particular, ERCC1 acts as a key component in DNA repair, as well as BRCA1 (9-12). RRM1 is a component of DNA and the essential enzyme producing the deoxynucleoside involved in DNA synthesis and 
repair $(13,14)$. Tubulin dimers consisting of TUBB3 compose microtubule polymers that interfere with the reaction to paclitaxel by slowing or blocking the transition from metaphase to anaphase in the mitotic cell cycle $(15,16)$.

Overall, these capable biomarkers have been demonstrated as prognostic and predictive markers in certain studies, but not in others (17-20). Accordingly, the present prospective, randomized, non-interventional study was performed to verify the predictive value of the protein expression of ERCC1, BRCA1, RRM1 and TUBB3 in patients with NSCLC that received adjuvant cisplatin-based chemotherapy at the Sun Yat-Sen University Cancer Center (Guangzhou, Guangdong, China).

\section{Materials and methods}

Patients and treatment. A total of 213 NSCLC patients were recruited in the present prospective, randomized, non-interventional study at the Sun Yat-Sen University Cancer Center between February 2009 and June 2013. All patients provided written informed consent and the present study was approved by the Ethics Committee of Sun Yat-Sen University Cancer Center. The baseline assessment prior to surgery involved obtaining the medical history of patients and performing physical, hematological and biochemical examinations, chest X-rays, electrocardiograms, pulmonary function tests, computed tomography of the thorax and abdomen, and magnetic resonance imaging of the brain. Bone scans were required only if bone metastasis was suspected. All patients received lobectomy or pneumonectomy. The expression of ERCC1, BRCA1, RRM1 and TUBB3 was tested following the surgical procedure. The pathological stage was identified post-operatively according to the 7th edition of the Union for International Cancer Control Tumor, Node, Metastasis (TNM) Classification for lung cancer (21).

Subsequent to surgery, the patients were randomly assigned to receive $75 \mathrm{mg} / \mathrm{m}^{2}$ cisplatin plus $75 \mathrm{mg} / \mathrm{m}^{2}$ docetaxel or $500 \mathrm{mg} / \mathrm{m}^{2}$ pemetrexed chemotherapy every three weeks for four cycles. Prior to the administration of the first cycle of chemotherapy within four weeks of the surgical procedure, the patients were assessed post-operatively, including a physical examination and a two-view chest X-ray. Prior to each chemotherapy cycle, the patients underwent a physical examination with routine biochemistry examination and blood counts. Patients were excluded if they possessed concurrent uncontrolled illness, or demonstrated an Eastern Cooperative Oncology Group (ECOG) performance status $>1$. Other exclusion criteria were significant weight loss $(\geq 5 \%)$, inadequate liver or renal function and an age $>80$ years old.

Immunohistochemical (IHC) and pathological assessments. A standard protocol was used for the immunostaining of the samples that were detected as NSCLC by hematoxylin and eosin staining. Briefly, formalin-fixed, paraffin-embedded specimens were sliced into $4 \mu \mathrm{m}$ sections and baked for $1 \mathrm{~h}$ at $65^{\circ} \mathrm{C}$. The specimens were exposed to $10 \mathrm{mM}$ citrate buffer $(\mathrm{pH}$ 6.0) for $10 \mathrm{~min}$. Tumor sections were incubated for $60 \mathrm{~min}$ with the mouse monoclonal anti-human ERCC1 antibody (clone, 4F9; \#UM500008; OriGene Technologies, Inc., Rockville, MD, USA; dilution, 1:150), rabbit polyclonal anti-BRCA1 antibody (\#AR345-5R; BioGenex Laboratories, Inc., San Ramon, CA,
USA; dilution, 1:50), rabbit monoclonal anti-RRM1 antibody (clone, EP242; \#AC-0217RUO; Epitomics, Abcam, Cambridge, UK; dilution, 1:100) and mouse monoclonal anti-TUBB3 antibody (clone SDL3D10; \#MU177-UC; BioGenex Laboratories, Inc.; dilution, 1:50). The tissue sections were incubated with polyclonal goat anti-rabbit (\#ab150077; Abcam; dilution, 1:200) and goat anti-mouse (\#ab150115; Abcam; dilution, 1:200) IgG biotinylated secondary antibodies for $30 \mathrm{~min}$ at $37^{\circ} \mathrm{C}$. The sections were then incubated with a streptavidin-horseradish peroxidase complex (Sigma-Aldrich, St. Louis, MO, USA) for 5 min at room temperature. Finally, the sections were developed with diaminobenzidine and counterstained with hematoxylin. Negative controls were also run simultaneously.

Each section of the tissue specimens was evaluated independently under a light microscope (CX21; Olympus Corporation, Tokyo, Japan) by two pathologists, and eight random fields were used to assess the expression levels of ERCC1, BRCA1, RRM1 and TUBB3, and also to calculate an average score. In addition, the two pathologists were blinded to the clinical status of the patients. For each patient specimen, these biomarkers were assessed by intensity, which was scored as follows: 0 , no staining; 1 , weak staining; 2 , moderate staining; and 3, strong staining.

Statistical analysis. The primary endpoint was DFS time, which was defined as the time from the date of surgery to the date of tumor recurrence or distant metastasis. The date was limited to the time of the last tumor assessment if disease recurrence or distant metastasis did not occur. The secondary endpoint was the overall survival (OS) time, which was defined as the time from the date of the surgical procedure to the date of mortality from any cause.

The Kaplan-Meier method was used to estimate the DFS and OS times using SPSS version 17 software (SPSS, Inc., Chicago, IL, USA). Pearson's $\chi^{2}$ test and Fisher's exact test were also applied to study the association between these biomarkers and patient characteristics that consisted of gender, age, histology, smoking status, alcohol intake and tumor stage. The DFS time was analyzed by subgroups using the Cox proportional hazards model, with variables consisting of age, gender, histology, smoking status, alcohol intake and tumor stage. All $\mathrm{P}$-values were two-sided and $\mathrm{P}<0.05$ was considered to indicate a statistically significant difference.

\section{Results}

Patient characteristics. During the follow-up period, 34 patients experienced recurrence, of which 22 patients had succumbed to cancer by the cut-off date for analysis (June 1, 2014). The median follow-up period was 28.0 months (range, 4.9-49.5 months). Table I lists the characteristics of the patients and the pathological findings. For all 84 patients in the present study, the median age at disease diagnosis was 58 years, ranging between 37 and 76 years old, with $68 \%$ of the patients being men. The most common histological type was adenocarcinoma (53 patients; 63\%), followed by squamous cell carcinoma (22 patients; 26\%) and other types (9 patients; $11 \%$ ), including large-cell carcinoma, bronchoalveolar carcinoma and mixed types. The number of patients with stage II and III tumors was $36(43 \%)$ and $48(57 \%)$, respectively. 
Table I. Patient characteristics according to the expression of ERCC1, BRCA1, RRM1 and TUBB3.

\begin{tabular}{|c|c|c|c|c|c|c|c|c|c|c|c|c|c|}
\hline \multirow[b]{2}{*}{ Characteristics } & \multirow{2}{*}{$\begin{array}{l}\text { Total, } \\
\mathrm{n}(\%)\end{array}$} & \multicolumn{3}{|c|}{ ERCC1 expression } & \multicolumn{3}{|c|}{ BRCA1 expression } & \multicolumn{3}{|c|}{ RRM1 expression } & \multicolumn{3}{|c|}{ TUBB3 expression } \\
\hline & & - & + & P-value & - & + & P-value & - & + & P-value & - & + & P-value \\
\hline NSCLC patients & $84(100)$ & 38 & 46 & & 73 & 11 & & 11 & 73 & & 8 & 76 & \\
\hline \multicolumn{14}{|l|}{ Gender } \\
\hline Female & $27(32)$ & 12 & 15 & 0.92 & 23 & 4 & 1.00 & 4 & 23 & 1.00 & 3 & 24 & 1.00 \\
\hline Male & $57(68)$ & 26 & 31 & & 50 & 7 & & 7 & 50 & & 5 & 52 & \\
\hline \multicolumn{14}{|l|}{ Age } \\
\hline$\leq 60$ & $66(79)$ & 33 & 33 & 0.09 & 56 & 10 & 0.50 & 8 & 58 & 0.91 & 6 & 60 & 1.00 \\
\hline$>60$ & $18(21)$ & 5 & 13 & & 17 & 1 & & 3 & 15 & & 2 & 16 & \\
\hline \multicolumn{14}{|l|}{ Smoking status } \\
\hline Smoker & $52(62)$ & 22 & 30 & 0.49 & 44 & 8 & 0.65 & 7 & 45 & 1.00 & 5 & 47 & 1.00 \\
\hline Non-smoker & $32(38)$ & 16 & 16 & & 29 & 3 & & 4 & 28 & & 3 & 29 & \\
\hline \multicolumn{14}{|l|}{ Alcohol Intake } \\
\hline Yes & $6(7)$ & 2 & 4 & 0.86 & 6 & 0 & $1.00^{\mathrm{a}}$ & 0 & 6 & $1.00^{\mathrm{a}}$ & 0 & 6 & $1.00^{\mathrm{a}}$ \\
\hline No & $78(93)$ & 36 & 42 & & 67 & 11 & & 11 & 67 & & 8 & 70 & \\
\hline \multicolumn{14}{|l|}{ Histology } \\
\hline Adenocarcinoma & $53(63)$ & 23 & 30 & 0.67 & 45 & 8 & 0.76 & 8 & 45 & 0.76 & 2 & 51 & 0.03 \\
\hline $\begin{array}{l}\text { Squamous cell } \\
\text { carcinoma }\end{array}$ & $22(26)$ & 12 & 10 & & 20 & 2 & & 2 & 20 & & 3 & 19 & \\
\hline Others & $9(11)$ & 4 & 5 & & 8 & 1 & & 1 & 8 & & 3 & 6 & \\
\hline \multicolumn{14}{|l|}{ Stage } \\
\hline II & $36(43)$ & 16 & 20 & 0.90 & 34 & 2 & 0.15 & 6 & 30 & 0.60 & 4 & 32 & 1.00 \\
\hline $\mathrm{III}^{\mathrm{a}}$ & $48(57)$ & 22 & 26 & & 39 & 9 & & 6 & 42 & & 4 & 41 & \\
\hline
\end{tabular}

P-values were calculated using Pearson's $\chi^{2}$ test. ${ }^{a}$ Calculated using Fisher's exact probablility. -, no expression; +, expression; NSCLC, non-small cell lung cancer; ERCC1, excision repair cross-complementation group 1; BRCA1, breast cancer 1; RRM1 ribonucleotide reductase M1; TUBB3, class III $\beta$-tubulin.



Figure 1. Procedure of patient selection. Reasons for withdrawal consisted of patient decision $(n=5)$, Eastern Cooperative Oncology Group performance status $\geq 2(n=5)$, mortality $(n=1)$ and did not complete four cycles of chemotherapy $(n=8)$.

IHC assessment. All patients were divided into two groups, consisting of the negative group, with a staining score of 0 , and the positive group, with a staining score of 1-3, according to the expression of ERCC1, BRCA1, RRM1 and TUBB3, respectively (Fig. 1). Fig. 2 shows the appearance of specimens stained for the expression of ERCC1, BRCA1, RRM1 and TUBB3 in squamous cell carcinoma. The nuclear expression of ERCC1 was identified in 46 out of 84 tissues (54.8\%), cytoplasmic BRCA1 expression was identified in 11 out of 84 tissues (13.1\%), cytoplasmic RRM1 expression was identified in 73 out of 84 tissues $(86.9 \%)$ and cytoplasmic TUBB3 expression was identified in 76 out of 84 tissues $(90.5 \%)$. There was a notable positive association between pathological histology and TUBB3 expression $(\mathrm{P}=0.03)$, but not expression of ERCC1, BRCA1 or RRM1. However, there was no significant association between the expression of these biomarkers and the clinicopathological variables, which consisted of age, gender, smoking status, alcohol intake and TNM stage.

Survival analysis. The DFS time was significantly longer in the ERCC1-negative group compared with the ERCC1-positive group (median, 33.6 vs. 19.0 months; $\mathrm{P}=0.032$; Fig. 3A). A similar result was demonstrated in the BRCA1-positive and BRCA1-negative groups (median, 24.4 vs. 23.9 months; $\mathrm{P}=0.019$; Fig. 3B), but not in the RRM1-positive and RRM1-negative groups (median, 23 vs. 24 months; $\mathrm{P}=0.205$; Fig. 3C) or TUBB3-positive and TUBB3-negative 
Table II. Univariate analysis and multivariate analysis for presictors of disease-free survival.

\begin{tabular}{|c|c|c|c|c|c|c|}
\hline \multirow[b]{2}{*}{ Variables } & \multicolumn{3}{|c|}{ Univariate analysis } & \multicolumn{3}{|c|}{ Multivariate analysis } \\
\hline & HR & CI & P-value & HR & $\mathrm{CI}$ & P-value \\
\hline \multicolumn{7}{|l|}{ Gender } \\
\hline Male vs. female & 0.949 & $0.462-1.949$ & 0.887 & 0.868 & $0.354-2.133$ & 0.758 \\
\hline \multicolumn{7}{|l|}{ Age } \\
\hline$>60$ vs. $\leq 60$ years & 1.934 & $0.922-4.057$ & 0.081 & 1.683 & $0.700-4.047$ & 0.245 \\
\hline \multicolumn{7}{|l|}{ Pathology } \\
\hline $\begin{array}{l}\text { Others vs. squamous cell } \\
\text { carcinoma vs. adenocarcinoma }\end{array}$ & 1.209 & $0.751-1.949$ & 0.425 & 1.643 & $0.949-2.845$ & 0.076 \\
\hline \multicolumn{7}{|l|}{ Smoking status } \\
\hline Smoker vs. non-smoker & 0.794 & $0.387-1.630$ & 0.530 & 0.708 & $0.285-1.758$ & 0.457 \\
\hline \multicolumn{7}{|l|}{ Drink } \\
\hline Yes vs. no & 0.971 & $0.245-4.303$ & 0.971 & 1.737 & $0.341-8.844$ & 0.506 \\
\hline \multicolumn{7}{|l|}{ Stage } \\
\hline Stage IIIa vs. stage II & 2.352 & $1.097-5.044$ & 0.028 & 2.381 & $1.069-5.304$ & 0.034 \\
\hline \multicolumn{7}{|l|}{ ERCC1 expression } \\
\hline Present vs. absent & 2.166 & $1.049-4.474$ & 0.037 & & & \\
\hline \multicolumn{7}{|l|}{ BRCA1 expression } \\
\hline Present vs. absent & 2.419 & $1.127-5.193$ & 0.023 & & & \\
\hline \multicolumn{7}{|l|}{ RRM1 expression } \\
\hline Present vs. absent & 0.568 & $0.234-1.379$ & 0.212 & 0.399 & $0.156-1.022$ & 0.055 \\
\hline \multicolumn{7}{|l|}{ TUBB3 expression } \\
\hline Present vs. absent & 1.874 & $0.448-7.842$ & 0.390 & 1.677 & $0.345-8.154$ & 0.521 \\
\hline \multicolumn{7}{|l|}{ ERCC1+BRCA1 expression } \\
\hline $\begin{array}{l}\text { ERCC1 or BRCA1 present vs. } \\
\text { ERCC1 and BRCA1 absent }\end{array}$ & 3.102 & $1.343-7.163$ & 0.008 & 2.968 & $1.203-7.322$ & 0.018 \\
\hline
\end{tabular}

$\mathrm{P}<0.05$ was considered to indicate a statistically sigificant difference, and Cox proportional hazards model was used to obtain the P-values. HR, hazard ratio; CI, confidence interval; ERCC1, excision repair cross-complementation group 1; BRCA1, breast cancer 1; RRM1, ribonucleotide reductase M1; TUBB3, class III $\beta$-tubulin.

groups (median, 33.4 vs. 23.3 months; P=0.382; Fig. 3D). In addition, the combined expression of ERCC1 and BRCA1 was assessed to determine the DFS time. A markedly increased benefit from chemotherapy was identified in the absence of ERCC1 and BRCA1 expression compared with the presence of either ERCC1 or BRCA1 expression (median, 32.2 vs. 14.8 months; $\mathrm{P}=0.005$; Fig. $3 \mathrm{E}$ ). However, the OS time was not significantly different between any of the four biomarkers (data not shown) and the combination of ERCC1 and BRCA1 expression (median, 32.2 vs. 23.4 months; $\mathrm{P}=0.117$; Fig. 3F).

From the output of Cox regression, a series of factors were assessed, consisting of age, gender, smoking status, alcohol intake, histology, pathological staging, ERCC1, BRCA1, RRM1 and TUBB3 expression, and the combination of ERCC1 and BRCA1 expression. These factors were assessed using the univariate Cox regression analysis, as reported in Table II, to assess the impact of the factors on the DFS time of patients with NSCLC. The variables found to impact DFS time in the univariate analysis were ERCC1 [hazard ratio (HR), 2.166; 95\% confidence interval $(\mathrm{CI}), 1.049-4.474 ; \mathrm{P}=0.037]$, BRCA1 (HR, 2.419; 95\% CI 1.127-5.193; $\mathrm{P}=0.023$ ), tumor stage (HR, 2.352; 95\% CI 1.097-5.044; $\mathrm{P}=0.028)$ and the combination of ERCC1 and BRCA1 expression (HR, 3.102; 95\% CI 1.343-7.163; $\mathrm{P}=0.008)$. The variables, with the exception of ERCC1 and BRCA1, which were excluded to avoid confounding bias, were also used in the multivariate analysis model. In the multivariate analysis model, the results indicated that the predominant predictors of DFS time were the combination of ERCC1 and BRCA1 expression (HR, 2.968; 95\% CI, 1.203-7.322; $\mathrm{P}=0.018)$ and tumor stage $(\mathrm{HR}, 2.381 ; 95 \% \mathrm{CI}$, 1.069-5.304; $\mathrm{P}=0.034)$.

\section{Discussion}

Despite the development of novel treatments for patients with resected NSCLC, cisplatin agents have remained as the standard first-line treatment. However, the positive response and overall survival rates differ in patients with NSCLC, as well as the toxicities $(4,22,23)$. Therefore, the detection of genes, proteins and RNA may facilitate the selection of individuals or groups that may benefit most from adjuvant chemotherapy and reduce adverse events. The results of the present study revealed that the group of post-operative NSCLC patients administered 

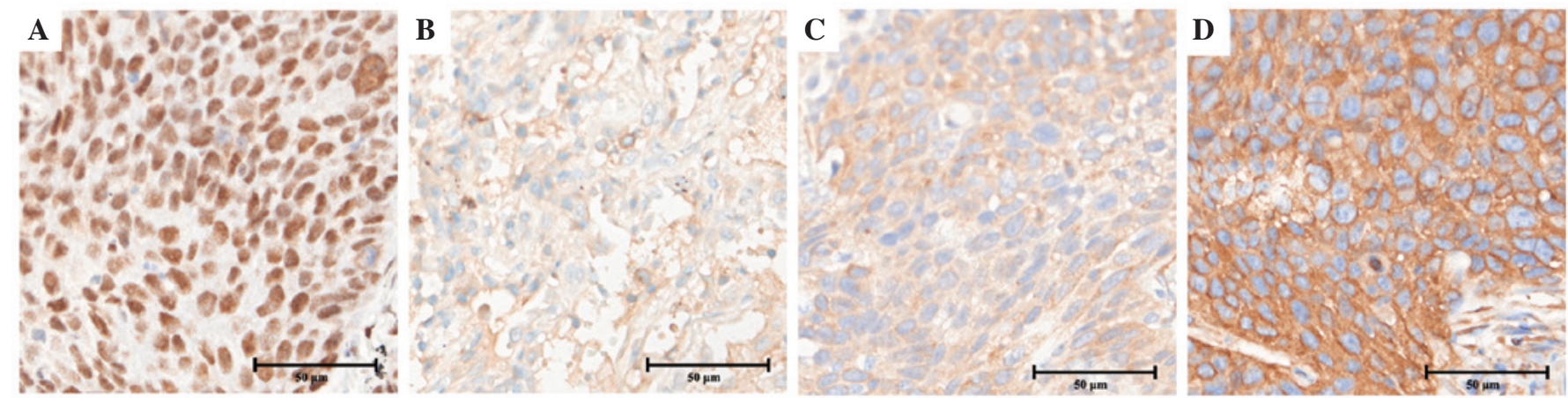

Figure 2. Immunohistochemical staining of squamous cell carcinoma. The tumor specimens (original magnification, $\mathrm{x} 400$ ) reveal strong expression (staining score 3) of (A) excision repair cross-complementation group 1, (B) breast cancer 1, (C) ribonucleotide reductase M1 and (D) class III $\beta$-tubulin.

A



C

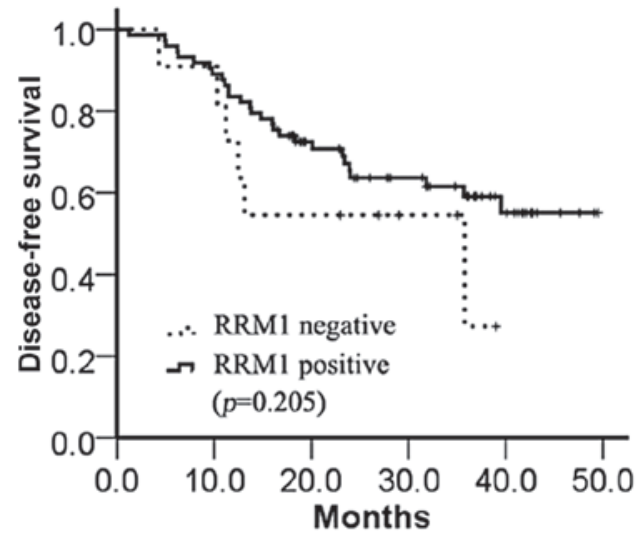

$\mathbf{E}$

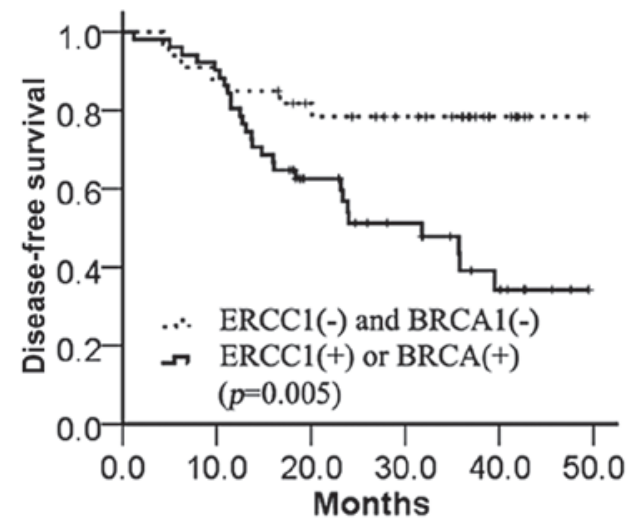

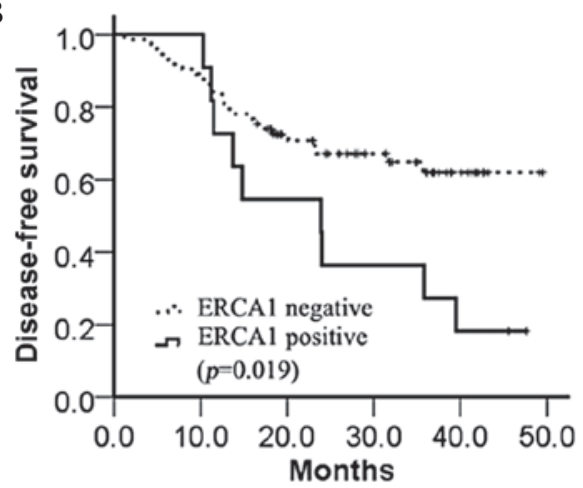

D

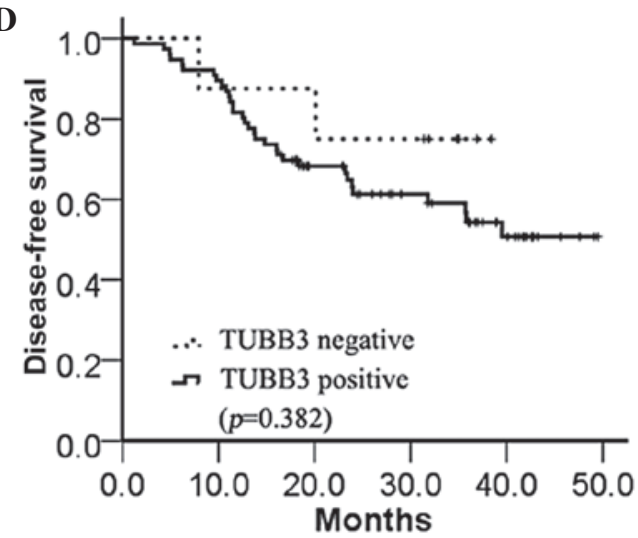

F



Figure 3. Kaplan-Meier estimates of the probability of survival with adjuvant cisplatin-based chemotherapy. (A) Disease-free survival according to ERCC1 expression (median, 33.6 vs. 19.0 months; $\mathrm{P}=0.032$ ). (B) Disease-free survival according to $\mathrm{BRCA} 1$ expression (median, 24.4 vs. 23.9 months; $\mathrm{P}=0.019$ ). (C) Disease-free survival according to RRM1 expression (median, 23.0 vs. 24.0 months; $\mathrm{P}=0.205$ ). (D) Disease-free survival according to TUBB3 expression (median, 33.4 vs. 23.3 months; $\mathrm{P}=0.382$ ). (E) Disease-free survival according to ERCC1 and BRCA1 expression (median, 32.2 vs. 14.8 months; $\mathrm{P}=0.005$ ). (F) Overall survival according to ERCC1 and BRCA1 expression (median, 32.2 vs. 23.4 months; $\mathrm{P}=0.117$ ). ERCC1, excision repair cross-complementation group 1; BRCA1, breast cancer 1; RRM1, ribonucleotide reductase M1; TUBB3, class III $\beta$-tubulin. 
with adjuvant cisplatin-based chemotherapy without ERCC1 expression demonstrated a significantly longer DFS time compared with the group that expressed ERCC1. The results from the assessment of BRCA1 expression were similar, with the lack of ERCC1 and BRCA1 expression prolonging the median DFS time by 14.6 and 0.5 months, respectively. The combination of ERCC1 and BRCA1 expression may be a more valuable prognostic predictor in patients with NSCLC administered with adjuvant cisplatin-based chemotherapy.

ERCC1 is the limiting factor in the nucleotide excision repair pathway that recognizes and removes platinum-induced nucleotide adducts $(24,25)$. In addition, ERCC1 may participate in the repair of DNA double-strand breaks (26). Overexpression of ERCC1 was involved in platinum resistance by prohibiting the activation of the EGFR pathway (27). These findings are consistent with the clinical evidence that ERCC1 in NSCLC inhibits platinum efficacy. The International Adjuvant Lung Cancer Trial (IALT) designed a prospective study to demonstrate that patients with completely resected NSCLC may demonstrate improved survival with the administration of adjuvant cisplatin-based chemotherapy in 2004 (28). Another study designed by IALT revealed that patients with ERCC1-negative tumors appeared to benefit from adjuvant cisplatin-based chemotherapy. However, patients with ERCC1-positive tumors did not benefit from the administered chemotherapy (7). Certain studies have also reported improved OS, DFS or progression-free survival times in patients with a low expression of ERCC1 compared with patients with high ERCC1 expression (20,28-30). The present results supported ERCC1 as a predictive biomarker for cisplatin-based chemotherapy. However, certain trials have failed to acquire similar results (31-33). This difference may be due to different antineoplastic protocols, different components of data and the presence of other genotypes that disturb the chemotherapeutic efficacy, which require additional investigation.

BRCA1 increases cisplatin sensitivity through inhibition of the c-Jun N-terminal kinase pathway in vitro $(34,35)$. A retrospective study by Taron et al revealed that the absence of BRCA1 expression resulted in high sensitivity to cisplatin compared with the cells that expressed BRCA1 (12). The present study also revealed that the tissues without BRCA1 expression demonstrated a longer DFS rate compared with patients that expressed BRCA1. However, the positive group had just 11 subjects. Therefore, a larger, multi-centric trial is required. As ERCC1 and BRCA1 are each associated with nucleotide excision repair, the present study hypothesized that the benefit from chemotherapy may be clearer when the expression of ERCC1 and BRCA1 were combined to assess survival. RRM1 is involved in DNA repair systems, similar to ERCC1 and BRCA1, as one of the targets of gemcitabine (36). Rosell et al demonstrated RRM1 to be a crucial predictive biomarker of survival in gemcitabine-treated patients with advanced NSCLC (37). TUBB3 has been investigated to determine the role of this gene in resistance to paclitaxel and docetaxel. TUBB3 is also an independent prognostic marker in patients with resected NSCLC that have not received chemotherapy (38-40). In the present study, the expression of RRM1 andTUBB3 was not associated with the DFS time of patients with NSCLC that received adjuvant cisplatin-based chemotherapy. The difference in the OS time was not significant in any of the four biomarkers. There are certain points that should be noted. Firstly, it is necessary to prolong the follow-up period to reflect the population outcome. Secondly, the sample size in the present study was too small to detect a difference in OS time.

In conclusion, the present study demonstrates that the expression of ERCC1, as detected by immunohistochemistry, acts as a predictive biomarker for cisplatin-based post-operative chemotherapy in patients with NSCLC. The expression of BRCA1 and ERCC1 may be an indicator for the lack of benefit of cisplatin-based adjuvant chemotherapy, but an enlargement of the sample size is required. Patients lacking ERCC1 and BRCA1 expression are likely to experience an increased benefit from adjuvant cisplatin-based chemotherapy.

\section{Acknowledgements}

This study was supported by the Science and Technology Project of Guangdong Province, China (grant no., 2010B031600315) and the National Natural Science Foundation of China (grant no., 81372568).

\section{References}

1. Jemal A, Bray F, Center MM, Ferlay J, Ward E and Forman D: Global cancer statistics. CA Cancer J Clin 61: 69-90, 2011.

2. Lozano R, Naghavi M, Foreman K, et al: Global and regional mortality from 235 causes of death for 20 age groups in 1990 and 2010: A systematic analysis for the Global Burden of Disease Study 2010. Lancet 380: 2095-2128, 2012.

3. Devesa SS, Bray F, Vizcaino AP and Parkin DM: International lung cancer trends by histologic type: Male:female differences diminishing and adenocarcinoma rates rising. Int J Cancer 117: 294-299, 2005.

4. NSCLC Meta-analyses Collaborative Group, Arriagada R, Auperin A, Burdett S, et al: Adjuvant chemotherapy, with or without postoperative radiotherapy, in operable non-small-cell lung cancer: Two meta-analyses of individual patient data. Lancet 375: 1267-1277, 2010.

5. Pignon JP, Tribodet H, Scagliotti GV, et al; LACE Collaborative Group: Lung adjuvant cisplatin evaluation: A pooled analysis by the LACE Collaborative Group. J Clin Oncol 26: 3552-3559, 2008.

6. Reck M, Heigener DF, Mok T, Soria JC and Rabe KF: Management of non-small-cell lung cancer: recent developments. Lancet 382: 709-719, 2013.

7. Olaussen KA, Dunant A, Fouret P, et al; IALT Bio Investigators: DNA repair by ERCC1 in non-small-cell lung cancer and cisplatin-based adjuvant chemotherapy. N Eng1 J Med 355: 983-991, 2006.

8. Vilmar A and Sørensen JB: Excision repair cross-complementation group 1 (ERCC1) in platinum-based treatment of non-small cell lung cancer with special emphasis on carboplatin: A review of current literature. Lung Cancer 64: 131-139, 2009.

9. Reed E: Platinum-DNA adduct, nucleotide excision repair and platinum based anti-cancer chemotherapy. Cancer Treat Rev 24: 331-344, 1998.

10. Simon GR, Ismail-Khan R and Bepler G: Nuclear excision repair-based personalized therapy for non-small cell lung cancer: From hypothesis to reality. Int J Biochem Cell Biol 39: 1318-1328, 2007.

11. Quinn JE, James CR, Stewart GE, et al: BRCA1 mRNA expression levels predict for overall survival in ovarian cancer after chemotherapy. Clin Cancer Res 13: 7413-7420, 2007.

12. Taron M, Rosell R, Felip E, et al: BRCA1 mRNA expression levels as an indicator of chemoresistance in lung cancer. Hum Mol Genet 13: 2443-2449, 2004.

13. Mann GJ, Musgrove EA, Fox RM and Thelander L: Ribonucleotide reductase M1 subunit in cellular proliferation, quiescence, and differentiation. Cancer Res 48: 5151-5156, 1988.

14. Engström Y, Eriksson S, Jildevik I, Skog S, Thelander L and Tribukait B: Cell cycle-dependent expression of mammalian ribonucleotide reductase. Differential regulation of the two subunits. J Biol Chem 260: 9114-9116, 1985. 
15. Jordan MA, Toso RJ, Thrower D and Wilson L: Mechanism of mitotic block and inhibition of cell proliferation by taxol at low concentrations. Proc Natl Acad Sci USA 90: 9552-9556, 1993.

16. Sève $\mathrm{P}$, Isaac $\mathrm{S}$, Trédan $\mathrm{O}$, et al: Expression of class III $\beta$-tubulin is predictive of patient outcome in patients with non-small cell lung cancer receiving vinorelbine-based chemotherapy. Clin Cancer Res 11: 5481-5486, 2005.

17. Bepler G, Williams C, Schell MJ, et al: Randomized international phase III trial of ERCC1 and RRM1 expression-based chemotherapy versus gemcitabine/carboplatin in advanced non-small-cell lung cancer. J Clin Oncol 31: 2404-2412, 2013.

18. Tiseo M, Bordi P, Bortesi B, Boni C, et al; Bio-FAST trial group: ERCC1/BRCA1 expression and gene polymorphisms as prognostic and predictive factors in advanced NSCLC treated with or without cisplatin. Br J Cancer 108: 1695-1703, 2013.

19. Booton R, Ward T, AshcroftL,Morris J,Heighway J and Thatcher N ERCC1 mRNA expression is not associated with response and survival after platinum-based chemotherapy regimens in advanced non-small cell lung cancer. J Thorac Oncol 2: 902-906, 2007.

20. Cobo M, Isla D, Massuti B, et al: Customizing cisplatin based on quantitative excision repair cross-complementing $1 \mathrm{mRNA}$ expression: A phase III trial in non-small-cell lung cancer. J Clin Oncol 25: 2747-2754, 2007.

21. Sobin LH, Gospodarowicz MK and Wittekind C (eds): Lung and Pleural Tumors. In: TNM Classification of Malignant Tumors. 7th edition. Wiley-Blackwell, Hoboken, NJ, pp136-148, 2010.

22. Arriagada R, Bergman B, Dunant A, Le Chevalier T, Pignon JP and Vansteenkiste J; International Adjuvant Lung Cancer Trial Collaborative Group: Cisplatin-based adjuvant chemotherapy in patients with completely resected non-small-cell lung cancer. N Engl J Med 350: 351-360, 2004.

23. Douillard JY, Rosell R, De Lena M, et al: Adjuvant vinorelbine plus cisplatin versus observation in patients with completely resected stage IB-IIIA non-small-cell lung cancer (Adjuvant Navelbine International Trialist Association [ANITA]): A randomised controlled trial. Lancet Oncol 7: 719-727, 2006.

24. Mu D, Hsu DS and Sancar A: Reaction mechanism of human DNA repair excision nuclease. J Biol Chem 271: 8285-8294, 1996.

25. Zamble DB, Mu D, Reardon JT, Sancar A and Lippard SJ: Repair of cisplatin - DNA adducts by the mammalian excision nuclease. Biochemistry 35: 10004-10013, 1996.

26. De Silva IU, McHugh PJ, Clingen PH and Hartley JA: Defining the roles of nucleotide excision repair and recombination in the repair of DNA interstrand cross-links in mammalian cells. Mol Cell Biol 20: 7980-7990, 2000.

27. Lian S, Su H, Zhao BX, Liu WY, Zheng LW and Miao JY: Synthesis and discovery of pyrazole-5-carbohydrazide $\mathrm{N}$-glycosides as inducer of autophagy in A549 lung cancer cells. Bioorg Med Chem 17: 7085-7092, 2009.
28. Holm B, Mellemgaard A, Skov T and Skov BG: Different impact of excision repair cross-complementation group 1 on survival in male and female patients with inoperable non-small-cell lung cancer treated with carboplatin and gemcitabine. J Clin Oncol 27: 4254-4259, 2009.

29. Lee SH, Noh KB, Lee JS, et al: Thymidylate synthase and ERCC1 as predictive markers in patients with pulmonary adenocarcinoma treated with pemetrexed and cisplatin. Lung Cancer 81: 102-108, 2013.

30. Lord RV, Brabender J, Gandara D, et al: Low ERCC1 expression correlates with prolonged survival after cisplatin plus gemcitabine chemotherapy in non-small cell lung cancer. Clin Cancer Res 8: 2286-2291, 2002

31. Zheng Z, Chen T, Li X, Haura E, Sharma A and Bepler G: DNA synthesis and repair genes RRM1 and ERCC1 in lung cancer. N Engl J Med 356: 800-808, 2007.

32. Friboulet L, Olaussen KA, Pignon JP, et al: ERCC1 isoform expression and DNA repair in non-small-cell lung cancer. N Engl J Med 368: 1101-1110, 2013

33. Lee KH, Min HS, Han SW, et al: ERCC1 expression by immunohistochemistry and EGFR mutations in resected non-small cell lung cancer. Lung Cancer 60: 401-407, 2008.

34. Harkin DP, Bean JM, Miklos D, et al: Induction of GADD45 and JNK/SAPK-dependent apoptosis following inducible expression of BRCA1. Cell 97: 575-586, 1999.

35. Potapova O, Haghighi A, Bost F, et al: The Jun kinase/ stress-activated protein kinase pathway functions to regulate DNA repair and inhibition of the pathway sensitizes tumor cells to cisplatin. J Biol Chem 272: 14041-14044, 1997.

36. Pitterle DM, Kim YC, Jolicoeur EM, Cao Y, O'Briant KC and Bepler G: Lung cancer and the human gene for ribonucleotide reductase subunit M1 (RRM1). Mamm Genome 10: 916-922, 1999.

37. Rosell R, Danenberg KD, Alberola V, et al; Spanish Lung Cancer Group: Ribonucleotide reductase messenger RNA expression and survival in gemcitabine/cisplatin-treated advanced non-small cell lung cancer patients. Clin Cancer Res 10: 1318-1325, 2004

38. Koh Y, Jang B, Han SW, et al: Expression of class III beta-tubulin correlates with unfavorable survival outcome in patients with resected non-small cell lung cancer. J Thorac Oncol 5: 320-325, 2010.

39. Burkhart CA, Kavallaris M and Band Horwitz S: The role of $\beta$-tubulin isotypes in resistance to antimitotic drugs. Biochim Biophys Acta 1471: O1-O9, 2001.

40. Gan PP, Pasquier E and Kavallaris M: Class III $\beta$-tubulin mediates sensitivity to chemotherapeutic drugs in non small cell lung cancer. Cancer Res 67: 9356-9363, 2007. 